\title{
Pathogenic Bacteria Associated with Different Public Environmental Sites in Mecca City
}

\author{
Samy S. Ashgar, Hamdy M. El-Said \\ Medical Microbiology Department, College of Medicine, Umm Al-Qura University, Mecca, Saudi Arabia \\ Email: hamdimustafa1@gmail.com
}

Received September 30, 2012; revised November 5, 2012; accepted November 13, 2012

\begin{abstract}
Background: The hygiene of environmental surfaces from shopping, ATM machines, telephones and computers and miscellaneous sites play role in spreading fecal and total coliform bacteria as well as pathogenic bacteria. Objectives: This study addresses the contaminated common sites by pathogenic or potentially pathogenic bacteria in Mecca, SA. Materials and Methods: A total 648 swab samples were collected and analyzed for presence or absence of pathogenic bacteria. Results: Of the total samples 422 were negative bacterial count (71\%) and 226 (29\%) were positive. All collected samples (100\%) of glass windows in the fish markets were bacterial counted; most dominated was Bacillus spp. $(\mathrm{n}=97)$ and the highest population of species was Enterococcus faecalis $(\mathrm{n}=40)$ and E. coli $(\mathrm{n}=16)$. Conclusion: Some public sites were very contaminated with different types of fecal coliform group of bacteria such as shopping cart handles, inner surfaces and child seats in supermarkets, and the glass windows in the fish market. Acinetobacter haemolyticus and other hemolytic bacteria were isolated from more than site.
\end{abstract}

Keywords: Keyboards; ATM; Pathogenic Bacteria; Mecca; Enterococcus faecalis

\section{Introduction}

Scientific research has shown that commonly used surfaces such as computers, telephones, headsets, desks and ATM machines are potential sources of infectious bacteria and viruses leading to the spread of colds, flu, sickness and diarrhea [1-3]. They are constantly in contact with the environment wherever we go. Germs can survive in the microscopic grooves and cracks on surfaces and will go unnoticed. Oils in the skin, dust, grime, moisture and warmth from central heating systems provide an ideal environment for these germs to accumulate.

Cold and flu viruses can survive on dry surfaces for more than 48 hours, while some bacteria, such as E. coli, can survive on dry surfaces for months on end. Soft, wet surfaces (particularly those with plenty of food) are perfect for bacteria. Cloth, sponges and carpets that have gotten wet are excellent living places for bacteria because it protects them from exposure to the environment, dry air or sunlight [4].

Bacteria that can cause severe gastroenteritis have been found on ATM machine keypads. Roxburgh [5] demonstrate that germs can be readily transferred from your hands to almost any frequently used surface. The role of fomites in the transmission of disease remains a controversial subject. Some epidemiological studies have suggested that contaminated surfaces may play a role in the spread of respiratory viruses and laboratory studies have supported this hypothesis [6-8]. Other studies have implicated environmental surfaces in the transmission of bacteria $[2,9,10]$. However, the role of environmental surfaces in the transmission of disease remains an issue of scientific debate and fundamental information concerning the microbial transfer rates from environmental surfaces to the hands and from the hands to the mouth remains scarce. Aim of this manuscript was to evaluate the presence or absence of pathogenic bacteria from different public sites in Mecca, SA.

\section{Materials \& Methods}

\subsection{Samples Collection}

Samples were collected from the following sites in Mecca city: 1) Swabs of shopping trolleys in supermarkets; 2) Swabs of the existing holes in the glass fish market suburb; 3) Swabs from the handles of the doors of ATM; 4) Swabs of refrigerated water taps in the streets; 5) Swabs from the mike, pens and keyboards in the public halls; 6) Swabs from handles laundry in public restaurants; and 7) Swabs from the surfaces of cans of carbonated drinks.

\subsection{Transportation of the Samples}

All samples were collected on Amies transport swabs media and transported to the microbiology research labo- 
ratory without any delay.

\subsection{Cultivation of Samples}

All samples were collected processed in the research laboratory according to the standard microbiological methods under complete aseptic conditions. The swabs were inoculated on MacConkey agar (Oxoid, England), blood agar, bile esculin agar (Oxoid, England), mannitol salt agar (Oxoid, England) andnutrient agar (Oxoid, England) and incubated at $37^{\circ} \mathrm{C}$ under aerobic conditions.

\subsection{Isolation and Identification of Bacteria}

All bacteria were isolated and identified according to the conventional microbiological methods as described in Burnett and Crocker [11], and Goldman and Green [12].

\subsubsection{Staphylococcus aureus}

Staphylococcus aureus was isolated from mannitol salt agar after an overnight incubation as a mannitol fermenting colonies. The identification was confirmed microscopically by the characteristic appearance as Gram positive cocci in clusters after being stained by Gram stain. Catalase test was also performed to differentiate between Staphylococcus (catalase positive) and Streptococcus (catalase negative). Then coagulase test was also performed to differentiate between Staphylococcus aure us (coagulase positive) and Staphylococcus spp. (coagulase negative).

\subsubsection{Pseudomonas aeruginosa}

Pseudomonas aeruginosa was isolated from nutrient agar medium which was grown after overnight incubation. The identification was confirmed by the characteristic appearance as colonies with greenish coloration and microscopically as Gram negative bacilli after being stained by Gram stain. An oxidase test was also performed, in which the organism is characteristic positive.

\subsubsection{Enterococcus faecalis}

Enterococcus faecalis isolated from Bile esculine agar medium which was grown after overnight incubation period. The identification was confirmed by the characteristic appearance as black colonies and microscopically Gram positive cocci in chains after being stained by Gram stain. Lancefield grouping test was also performed as group D.

\subsubsection{Bacillus spp.}

Bacillus spp. was isolated from Blood agar medium which was grown after an overnight incubation period. The identification was confirmed microscopically as Gram positive bacilli in chains.

\subsubsection{Biotyping of Enterobacteriaceae Isolates by API 20E System}

The API 20E system (Bio-Mérieux, Marcy l'Etoile, France) isan identification system for Enterobacteriaceae and other non-fastidious gram-negative rods. This system consists of 20 microtubes containing dehydrated substrates. These tests are inoculated with a bacterial suspension which reconstitutes the media. During incubation, metabolism produces color changes that are either spontaneous or revealed by the addition of reagents. The reactions are read according to the table for interpretation of reactions and the identification is obtained by referring to the Analytical Profile Index (API).

Procedure:

1) Preparation of the inoculums

A single well-isolated colony was selected from an isolation plate and carefully emulsified in sterile $\mathrm{NaCl}$ 0.85\% medium, pH 5.5 - 7.0 to achieve a homogeneous bacterial suspension.

2) Inoculation of the strip

With a pipette, the tests of Citrate utilization, Acetoin production and Gelatinase were filled with the bacterial suspension. Anaerobiosis was created in the tests Arginine dihydrolase, Lysine decarboxylase, Ornithine decarboxylase, $\mathrm{H}_{2} \mathrm{~S}$ production and Urease by overlaying with mineral oil. The incubation box of the strip was closed and incubated at $35^{\circ} \mathrm{C}-37^{\circ} \mathrm{C}$ for $18-24$ hours.

3) Reading the strip

After the incubation period $18-24$ hours at $35^{\circ} \mathrm{C}$ $37^{\circ} \mathrm{C}$, the strip was read by referring to interpretation of reactions. All spontaneous reactions were recorded on the result sheet.

\section{Results}

The quantitative analysis of all tested samples was 648, of which 422 was negative bacterial count (71\%). Alternatively, total positive samples were 226 (29\%) of counted bacteria Table 1. However, $100 \%$ positive results were recorded of samples collected from the glass windows in the fish market and 14\% negative results of swabs from the surfaces of cans of carbonated drinks. This is indicate that refrigeration keep out bacteria away. The most obvious way of solving the problem bacterial contamination is to keep places cool even glass windows in the fish market; also, is to regularly clean and disinfect the glass.

Contaminated sites were more frequently in some sites such as shopping cart handles, inner surfaces and child seats in supermarkets ( $\mathrm{n}=48)$, and refrigerated water taps in the streets $(n=47)$ than other sites; surfaces of cans of carbonated drinks $(n=13)$ and from handles laundry in public restaurants $(n=26)$. The most negative contaminated site was mike, pens and keyboards in the 
Table 1. Frequency and percentage of positive and negative collected samples.

\begin{tabular}{lccccc}
\hline & \multirow{2}{*}{$\begin{array}{c}\text { No.of } \\
\text { Locations }\end{array}$} & \multicolumn{5}{c}{ Result } \\
\cline { 3 - 6 } & Samples & Positive & $\%$ & Negative & $\%$ \\
\hline $\begin{array}{c}\text { Swabs from shopping cart } \\
\text { handles, inner surfaces and } \\
\text { child seats in supermarkets }\end{array}$ & 99 & 48 & 48 & 51 & 52 \\
$\begin{array}{c}\text { Swabs from the glass } \\
\text { windows in the fish market }\end{array}$ & 33 & 33 & 100 & 0 & 0 \\
$\begin{array}{c}\text { Swabs from slots, buttons in } \\
\text { the vicinity and handles of } \\
\text { the doors of ATM }\end{array}$ & 96 & 29 & 26 & 67 & 64 \\
$\begin{array}{c}\text { Swabs of refrigerated water } \\
\text { taps in the streets }\end{array}$ & 84 & 47 & 56 & 37 & 44 \\
$\begin{array}{c}\text { Swabs from the mike, pens } \\
\text { and keyboards in the public } \\
\text { halls }\end{array}$ & 157 & 30 & 16 & 127 & 84 \\
$\begin{array}{c}\text { Swabs from handles laundry } \\
\text { in public restaurants }\end{array}$ & 72 & 26 & 28 & 46 & 72 \\
$\begin{array}{c}\text { Swabs from the surfaces of } \\
\text { cans of carbonated drinks }\end{array}$ & 107 & 13 & 14 & 94 & 86 \\
$\quad$\begin{tabular}{c} 
Total \\
\hline
\end{tabular} & 648 & 226 & 29 & 422 & 71 \\
\hline
\end{tabular}

public halls $(\mathrm{n}=127)$ (Figure 1). Unexpectedly, more than half of samples collected from shopping trolleys in supermarkets were negative $(n=51)$ for presence of bacteria at all. A particular result could regard to just cleaning a trolleys in time or other reason not founded interpretation.

Quantitative bacterial analysis of isolates indicated presence of 226 bacterial isolates obtained from shopping cart handles, inner surfaces and child seats in supermarkets $(n=48)$; from the glass windows in the fish market $(\mathrm{n}=33)$; from slots, buttons in the vicinity and handles of the doors of ATM $(n=29)$; of refrigerated water taps in the streets $(n=47)$; from the mike, pens and keyboards in the public halls $(\mathrm{n}=30)$; from handles laundry in public restaurants $(n=26)$; from the surfaces of cans of carbonated drinks $(n=13)$. Table 2 shows per-

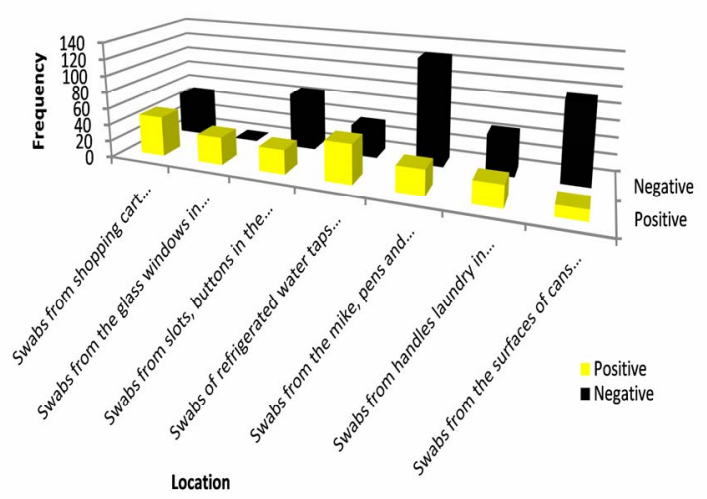

Figure 1. Positive and negative contaminated samples. centage of each infected site by Gram-positive or Gramnegative bacteria in relation to species type. From first inspection percentage of Bacillus spp. recorded the highest percentage between other isolated bacteria. This might due to their nature as spore former which could tolerate adverse conditions as well as flourish in normal circumstances.

All isolated bacteria were tested on blood agar medium to detect the potential pathogenic bacteria. Isolated Gram-negative bacteria (8 species) were varied from hemolytic bacteria (Acinetobacter haemolyticus), histamine producer (Morganella morganii), multidrug resistance (Pseudomonas aeruginosa) to coliform group ( $E$. coli, Enterobacter aerogenes and Citrobacter freundii). These bacteria found in public sites can pose serious health risks if uncontrolled. E. coli recorded 8 isolates of 48 positive contaminated sites (Figure 2).

There are several obvious differences between sites which bacteria were isolated from Mecca. The population density, the structures present and the atmospheric variability are all starkly diverse along this gradient, but we looked to address our hypothesis that the current cleaning regiment at the facilities and flat surfaces are not sufficient.

Bacillus spp. recorded 97 isolates from all sites where the highest one was from the mike, pens and keyboards in the public halls $(n=19)$ followed by the handles of the doors of ATM, from refrigerated water taps in the streets and from handles laundry in public restaurants were 18, 17 and 16 isolates, respectively. Enterococcus faecalis isolates detected in high rate at refrigerated water taps in the streets and shopping trolleys in supermarkets where 15 and 14 were, respectively (Figure 3).

\section{Discussion}

This study concentrated mainly on pathogenic bacteria for the aim of work and not includes plate bacterial count for the tremendous number of collected samples. Many

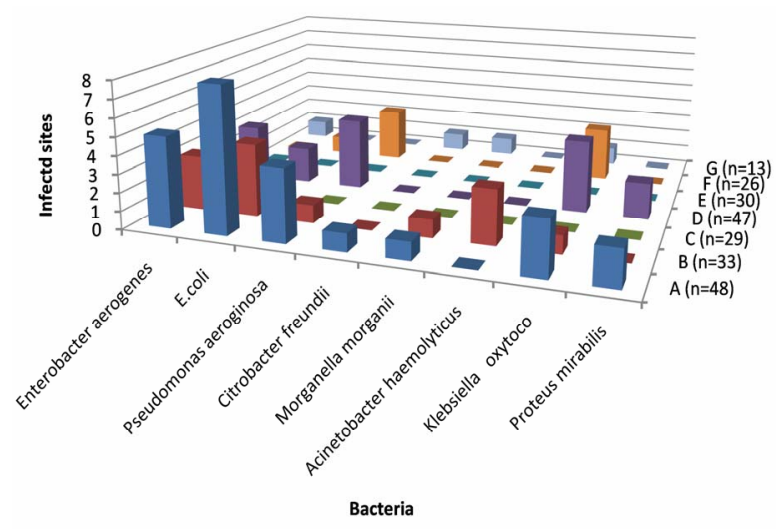

Figure 2. Speciation of gram-negative bacteria in relation to infected sites. 
Table 2. Percentage of bacterial diversity isolated from different sites in Mecca.

\begin{tabular}{|c|c|c|c|c|c|c|c|c|}
\hline \multirow{2}{*}{ Bacteria } & \multicolumn{7}{|c|}{ Location } & \multirow{2}{*}{$\begin{array}{c}\text { Total bacteria } \\
\text { number }\end{array}$} \\
\hline & $A(n=99)$ & $\mathrm{B}(\mathrm{n}=33)$ & $C(n=96)$ & $\mathrm{D}(\mathrm{n}=84)$ & $E(n=157)$ & $\mathrm{F}(\mathrm{n}=72)$ & $\mathrm{G}(\mathrm{n}=107)$ & \\
\hline Enterococcus faecalis & 29.2 & 21.2 & 6.9 & 31.9 & 0.0 & 7.7 & 0.0 & 40 \\
\hline Enterobacter aerogenes & 10.4 & 9.1 & 0.0 & 6.4 & 0.0 & 0.0 & 7.7 & 12 \\
\hline E. coli & 16.7 & 12.1 & 3.4 & 4.3 & 0.0 & 3.8 & 0.0 & 16 \\
\hline Staphylococcus aureus & 0.0 & 0.0 & 10.3 & 0.0 & 13.3 & 3.8 & 0.0 & 8 \\
\hline Pseudomonas aeroginosa & 8.3 & 3 & 0.0 & 8.5 & 0.0 & 11.5 & 0.0 & 12 \\
\hline Citrobacter freundii & 2.1 & 0.0 & 0.0 & 0.0 & 0.0 & 0.0 & 7.7 & 2 \\
\hline Morganella morganii & 2.1 & 3 & 0.0 & 0.0 & 0.0 & 0.0 & 7.7 & 3 \\
\hline Acinetobacter haemolyticus & 0.0 & 9.1 & 0.0 & 0.0 & 0.0 & 0.0 & 0.0 & 3 \\
\hline Klebsiella oxytoco & 6.3 & 3 & 0.0 & 8.5 & 0.0 & 11.5 & 7.7 & 12 \\
\hline Staphylococcus epidermidis & 6.3 & 6.1 & 17.2 & 0.0 & 23.3 & 0.0 & 0.0 & 17 \\
\hline Bacillus spp. & 14.6 & 33.3 & 62.1 & 36.2 & 63.3 & 61.5 & 69.2 & 97 \\
\hline Proteus mirabilis & 4.2 & 0.0 & 0.0 & 4.3 & 0.0 & 0.0 & 0.0 & 4 \\
\hline Number of positive infected sites & 48 & 33 & 29 & 47 & 30 & 26 & 13 & 226 \\
\hline
\end{tabular}

investigators have been studied solid surface bacterial infection in computer keyboard [13], mobile phones [14], computer keyboards and mice, elevator buttons and shopping carts [15] and currency notes [16]. They were not collected such huge samples number as in our case (648 samples).

A low positive percentage (16\%) results were detected from samples collected from the mike, pens and keyboards in the public halls. In contrast, Sheet of Protech IT hygiene (Technical release/162) [17] reported that there can be up to 400 times more bacteria on office desks and keyboards than toilet seats. In our view of point, the place of which samples collected, hygienic status of keyboards, cool of hall atmosphere could make such a difference.

Datta et al. [18] have isolated only Gram-positive bacteria Staphylococcus, Enterococcus, Micrococcus and

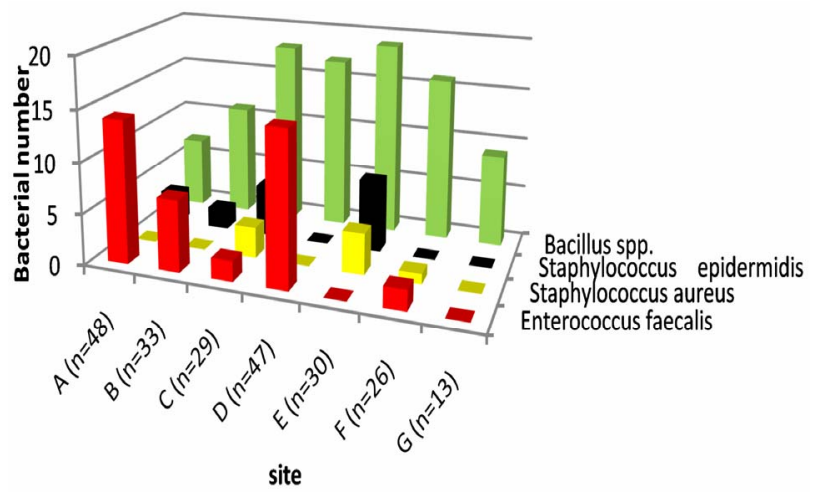

Figure 3. Speciation of Gram-positive bacteria in relation to infected sites.
Streptococcus from mobile phones. In this study a variety of media used in isolation process to fulfill the requirement of bacteria from different sites. It is obvious that large number of isolated Bacillus species (18 of 29 positive samples from slots, buttons in the vicinity and handles of the doors of ATM and 19 of 30 positive samples from the mike, pens and keyboards in the public halls) was transferred from finger tips or hands touching inanimate surfaces.

In comparison to many other studies, Yazah et al. [16] and Catãno et al. [19] obtained Gram-positive and Gramnegative bacteria in their work from currency notes and computer keyboards, curtains, cell phones, white coats, and ties, respectively. Such regarding results were typical to our results. Likewise, regular cleanness of contaminated sites with different disinfectants can minimize bacterial growth; it is extremely difficult to completely eliminate all bacteria from surfaces.

\section{Acknowledgements}

The authors would like to thank third-year students in the faculty of Medicine, umm Al-Qura University, Мecca, Saudi Arabia, for their cooperation in sample collection. Thanks also to Mr. Abdullah Apyeed and Mr. Assem Abdel-Shakoor for their assistance during this study.

\section{REFERENCES}

[1] F. X. Abad, R. M. Pinto and A. Bosch, "Survival of Enteric Viruses on Environmental Fomites," Applied Environmental Microbiology, Vol. 60, No. 10, 1994, pp. 37043710 . 
[2] S. Bures, J. T. Fishbain, C. F. T. Uyehara, J. M. Parker and B. W. Berg, "Computer Keyboards and Faucet Handles as Reservoirs of Nosocomial Pathogens in the Intensive Care Unit," American Journal of Infection Control, Vol. 28, No. 6, 2000, pp. 465-471. doi:10.1067/mic.2000.107267

[3] K. A. Reynolds, P. M. Watt, S. A. Boone and C. P. Gerba, "Occurrence of Bacteria and Bacterial Markers on Public Surfaces,” International Journal of Environmental Health Research, Vol. 15, No. 3, 2005, pp. 225-234. doi:10.1080/09603120500115298

[4] A. Musico, “Germs Are Everywhere!” 2010. http://EzineArticles.com/5427442

[5] J. S. Roxburgh, "Swabbing of ATM Machines,” Rentokil Initial Technical Report, Rentokil Initial PLC, London, 2005.

[6] J. Hendley, R. Wenzel and J. Gwaltney, “Transmission of Rhinovirus Colds by Self-Inoculation,” The New England Journal of Medicine, Vol. 288, No. 26, 1973, pp. 13611364. doi:10.1056/NEJM197306282882601

[7] S. Reed, “An Investigation of the Possible Transmission of Rhinovirus Colds through Indirect Contact," Journal of Hygiene (London), Vol. 75, No. 2, 1975, pp. 249-258. doi:10.1017/S0022172400047288

[8] C. B. Hall, R. G. Douglas Jr. and J. M. Geiman, "Possible Transmission by Fomites of Respiratory Syncytial Virus," The Journal of Infectious Diseases, Vol. 141, No. 1, 1980, pp. 98-102. doi:10.1093/infdis/141.1.98

[9] E. Ekanem, H. Dupont, L. Pickering, B. Selwyn and C. Hawkins, "Transmission Dynamics of Enteric Bacteria in Day-Care Centers,” American Journal of Epidemiology, Vol. 118, No. 6, 1983, pp. 562-572.

[10] M. Manning, L. Archibald, L. Bell, S. Banerjee and W. Jarvis, "Serratia marcescens Transmission in a Pediatric Intensive Care Unit: A Multifactorial Occurrence,” American Journal of Infection Control, Vol. 29, No. 2, 2001, pp. 115-119. doi:10.1067/mic.2001.114222
[11] D. Burnett and J. Crocker, "The Science of Laboratory Diagnosis,” 2nd Edition, John Wiley \& Sons Ltd., Chichester, 2006.

[12] E. Goldman and L. Green, "Practical Handbook of Microbiology,” 2nd Edition, CRC Press, Boca Raton, 2009.

[13] R. Marsden, “A Solid-Surfaced Infection Control Computer Keyboard,” 2009. http://www.cleankeys.nl/whitepaper.pdf

[14] F. Ulger, S. Esen, A. Dilek, K. Yanik, M. Gunaydin and H. Leblebicioglu, “Are We Aware How Contaminated Our Mobile Phones with Nosocomial Pathogens?” Annals of Clinical Microbiology and Antimicrobials, Vol. 8, No. 7, 2009, p. 7. doi:10.1186/1476-0711-8-7

[15] A. Al-Ghamdi, S. Abdelmalek, A. Ashshi, H. Faidah, H. Shukri and A. Jiman-Fatani, "Bacterial Contamination of Computer Keyboards and Mice, Elevator Buttons and Shopping Carts," African Journal of Microbiology Research, Vol. 5, No. 23, 2011, pp. 3998-4003.

[16] A.Yazah, J. Yusuf and A. Agbo, "Bacterial Contaminants of Nigerian Currency Notes and Associated Risk Factors," Research Journal of Medical Sciences, Vol. 6, No. 1, 2012, pp. 1-6. doi:10.3923/rjmsci.2012.1.6

[17] Protech IT Hygiene, “Technical Release/162: Hygiene Risks from I.T. Equipment,” 2012. http://www.corpteluk.com/webtop/modules/_repository/d ocuments/TechnicalRelease-Hygiene.pdf

[18] P. Datta, H. Rani, J. Chander and V. Gupta, "Bacterial Contamination of Mobile Phones of Health Care Workers," Indian Journal of Medical Microbiology, Vol. 27, No. 3, 2009, pp. 279-281. doi:10.4103/0255-0857.53222

[19] J. Catãno, L. Echeverri and C. Szela, "Bacterial Contamination of Clothes and Environmental Items in a ThirdLevel Hospital in Colombia,” Interdisciplinary Perspectives on Infectious Diseases, Vol. 2012, 2012, Article ID: 507640. doi:10.1155/2012/507640 